\title{
"STEPS ON THE WAY TO SOCIAL INTEGRATION": INITIAL SOCIAL INTERACTIONS OF REFUGEES FROM SYRIA, IRAQ AND Afghanistan With THE HOST SOCIETY, THEIR RELEVANCE, ASSESSMENT AND IMPLICATIONS
}

Josef KoHLBACHER, Vienna

\section{Content}

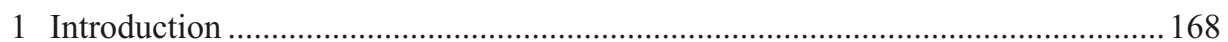

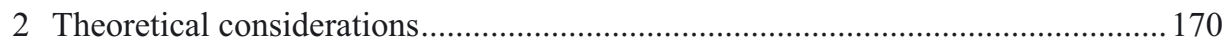

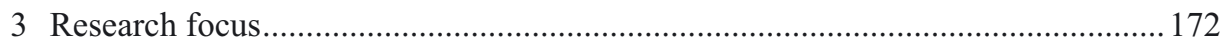

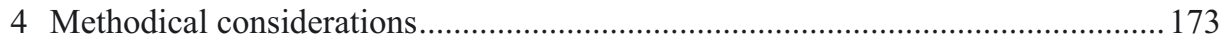

5 The relevance of weak and strong ties in the integration process ...........................173

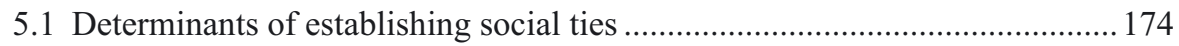

6 The relevance of social interactions with Austrians during the

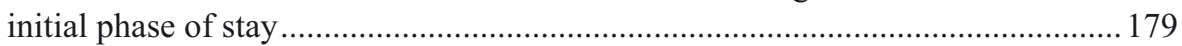

7 The relevance of social ties in structural integration: The long-term perspective . 182

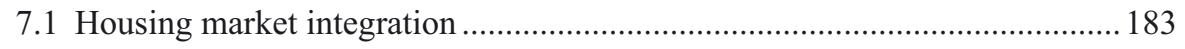

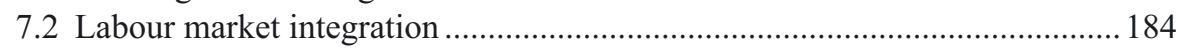

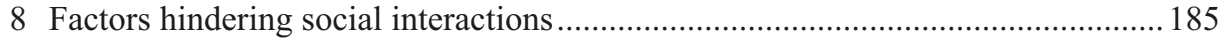

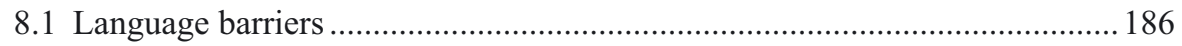

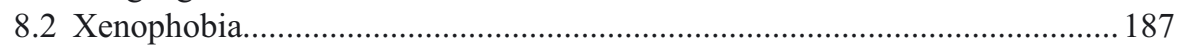

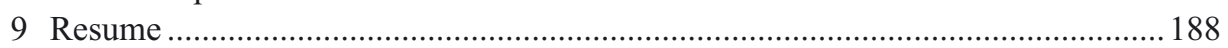

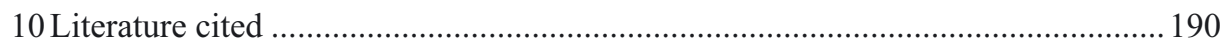




\section{Introduction}

This chapter will discuss some results from the pilot study interviews about early stage close contacts of refugees with Austrians, whether it be police officers, NGO representatives, (voluntary) refugee workers, language tutors, etc. The impact of direct interethnic contact of a very socio-economically and socio-demographically diverse sample of refugees with specific groups of Austrian people will be investigated. The analysis is based on the assumption that social integration is a process of change that involves both refugees and people of the host society and which starts immediately with the first contacts, though the extracted material only reflects the refugees' perspective of an interactive process.

The theoretical starting points can be found in the concept of "social integration" of Hartmut ESSER (2001) and in GRANOVETTER's (1973, 1985) theory about the relevance of weak and strong ties. Contact theory emphasises the attitude-shaping relevance of social interactions, particularly interethnic contacts which are especially important in reducing prejudices between different groups.

It is assumed that, due to these contacts, participating refugees generally gain an intial but more differentiated insight into the modes of interaction with Austrians as well as into the reality and characteristics of the receiving society. It can be shown that direct contact can either lead to delight or to some disappointment. One initial setting for interaction can be found in refugee homes or camps (e.g. Traiskirchen) that the respondents had to live in during their earliest days in Austria. Thus, interesting insights into the refugees' relationships with their immediate social environment in these homes are discussed. Some of the coincidental relationships of a rather weak tie quality proved a considerable degree of sustainability and helped the refugees greatly in gaining a foothold in the receiving society and establishing a social network of weak and even strong ties.

The focus on the particularity of individual experiences in unique societal locations and dynamic social processes forms the basis for a systematic comparison and interpretation of the pilot study interviews. The analysis aims to reveal structures of social processes of action as well as of possible resources for individual strategies of coping with challenges in the stages of arrival and early residence. A qualitative and interpretative research approach is used to understand how refugees participate in social contexts and make sense of them on their path to some social embeddedness in Austrian society. At the time of our interviews, the range of interactions with locals spanned from living in a flat together with Austrian friends to a complete absence of social contacts with the local population.

There is a broad range of experiences which obviously also depend on independent socio-economic and socio-demographic variables such as gender, education, language proficiency and country of origin. Only a minority of refugees reported experiences in which rejectionist attitudes were demonstrated towards them. This may be a visible 
outcome of the general mood of the political and media-fostered "welcome culture" which dominated the refugee discussion in Austria until the turn of the year 2015/16.

There is no doubt about the relevance of informal social contacts of immigrants with the established community. It can be assumed that, due to these contacts, participating migrants generally gain an initial and more differentiated insight into the modes of interaction with locals as well as into the reality and characteristics of the receiving society. Informal interethnic contacts and the establishment of weak ties pave the way for integration and are particularly relevant in the broader field of social integration and refugees.

In the bulk of the existing research, the outcome of contacts was analysed from the natives' perspective, whereas so far little attention has been paid to migrants and even less so to refugees. Our pilot study data now provides the opportunity to take a first look at this previously neglected group and at the relevance of social interaction, mainly during the early stage of stay, another innovative aspect of this analysis. In the narrative expressions about formal and informal social interactions collected in our sample, both conscious concerns and also unconscious cultural, societal and individual presuppositions and processes were mirrored.

This analysis is based on the assumption that social integration is a process of change and exchange that involves both refugees and people of the host society and which starts immediately with the first contacts, though the extracted material only reflects the refugees' perspective of this interactive process. Thus, we investigate the modes and consequences of interethnic social interactions and the resulting social ties in the refugees' everyday life and path to integration. The outcome of these interethnic contacts may emerge in different spheres: in attitudes, the transformation of weak ties into strong ones, the establishment of sustainable social networks and, last but not least, through the process of social and structural integration in general. The collected narratives are concerned with both the 'inner' and the 'outer' worlds of 'persons in social interaction', thus both a dynamic-interactive and socio-biographic approach is relevant.

One important initial setting for interactions can be found in refugee homes or camps (e.g. Traiskirchen, Lower Austria) where the respondents had to live upon arriving in Austria. Thus, interesting insights into the refugees' relationships with their immediate social environment in these homes are discussed. It can be shown that direct contact with NGO staff and volunteers can either lead to delight or to some disappointment, if as occurred in some cases - humanitarian commitment is not accompanied by sufficient awareness about refugee needs and the long-term implications of interethnic relations. Thus, these interactions may be either positively or negatively evaluated. Some of the coincidental relationships of rather weak tie quality with Austrians showed a strong degree of sustainability and were even transformed into strong ties that helped the refugees greatly in gaining a foothold in the receiving society and in establishing a broader network of weak and strong ties. 


\section{Theoretical considerations}

Past research on immigration has conceptualised the integration of immigrants into their new cultural and social environment as a multifaceted process involving different patterns and strategies (AgER and Strang 2008; Berry et al. 2002, Schibel et al., 2002; WALSH and HoRENCZYK 2001; WARD 1996; WARD et al. 2001). Furthermore, it is a multidimensional process in which individuals, refugee community organisations, government institutions, NGOs and receiving society individuals all have flexible roles (Ager 1999; Ager and Eyber, 2002; Ager and Strang, 2010). As integration is such a complex concept (CAstles et al. 2001; Musterd, 2003; Phillips, 2006), much has already been written about its many facets (i.e. Portes and Rumbaut 2001; ZetTer et al. 2002). Integration is a term often used in policy and research, but it can mean different things to different actors depending on their perspective, interests, assumptions and values (CASTLES et al. 2001). According to Kamali (1999), integration is a social issue rather than an administrative, bureaucratic, or legal one. Thus, the multi-level and processual nature of integration makes it necessary to relinquish conventional linear concepts.

Differences between 'structural integration' - the increased participation of migrants in the institutions of their new society (e.g. the paid labour and housing markets, social welfare systems) - and 'acculturation' (the processes by which migrants may develop their identities/practices over time within a host society) have been noted (CASTLES et al. 2002; Korac, 2003). Based on David Lockwood's (1964: 245) “relationships between the actors", ESSER (2001) tooalso differentiated between system integration on the macro level and social integration as a micro-level process. System integration is determined by supranational organisations, government institutions and municipalities. For social integration, individual motivations, orientations and intentions play a dominant role. There is some connection between both forms of integration, however EssER stated (2001, p. 4) "Es kann grundsätzlich eine Systemintegration auch ohne Sozialintegration geben." A high degree of system integration with a low level of social integration is also possible as well as the reverse situation (ESSER 1999, 2006). In any case, a certain degree of social integration is necessary to carry out social activities within the frame of social integration. Social integration can thus be defined as a process through which migrants are included in the core institutions, relations and statuses of the receiving society. For the migrants, integration refers to a process of learning the "binding rules" of a receiving society, an acquisition of rights, the access to positions and statuses, a formation process of personal relations to members of the receiving society and the developing feelings of belonging and identification.

Some previous studies (e.g. CAstles et al. 2002; Griffiths et al. 2005; Perry 2005; Spencer, 2006; Atfield et al 2007; Zetter et al. 2005) have recognised that the integration of refugees is rarely a straightforward process. Furthermore, some consider the notion of integration itself to be problematic in that it may be seen as a requirement imposed on migrants to 'fit in'. Hostile asylum policies and negative press coverage 
may also inhibit integration and exacerbate the harassment and racism that remains a feature of many refugees' lives (Quilgars et al. 2003; Craig et al. 2004a, b; Phillips, 2006). A model, proposed by WARD (1996), examines the different variables that play a role in the integration process. It takes into account personal factors, such as language fluency and integration strategies, in addition to situational factors, which include length of contact, cultural distance, and social support. This incorporates the coping framework and psychological and socio-cultural outcomes of integration (WARD et al. 2001).

There has also been an attempt to design a set of transferable indicators of integration that draws on social capital (Ager and Eyber, 2002). Ager and Strang (2004, 2008) have adopted PutnAm's (2007) model in distinguishing the concept of social network from that of social capital. The frequency of social contacts which are made with friends, relatives, and a range of organisations is an indicator of the strength of the individual's social networks (see below). Additionally, the type of contact is relevant. Essentially, bonding capital is characterised by so-called 'strong ties', like those that connect family members or close friends. Meanwhile, bridging capital refers to the weak ties that link people who are different from each other (KINDLER et al., 2015, p.13).

In this complex field it is important to take into account social ties as a relevant factor of social integration processes. Social interaction, be it intra-group or extra-group, has been characterised as "producing" weak ties (GranovetTER, 1973). These weak ties are important for refugees as they unite diverse networks and increase the resources available to network members (GURAK and CACES, 1992). These mechanisms have been investigated, for example, by Ager et al. (2002), Rosenberg (2008) and McMichael and MANDERSON (2004) in the case of refugees of different ethnic background. Obviously the individual characteristics of migrants also has effect on their capacity to establish social ties (and to mobilise resources), but also factors such as gender or social class are relevant.

The importance of intra-group contacts may decrease as a person's residential security increases and this process allows space for the establishment of closer ties with the established community of the receiving society. In an interactive process, the receiving society also has to learn new ways of interacting with the newcomers (HECKMANN, 2006, 18). Hollands (2002) found that due to social contacts, natives generally gain a more differentiated insight into the reality of refugees as well as into the characteristics of their own society. The same holds true from the refugees' perspective.

Social ties are an integral component of social networks. Closer ties allow the establishment of social networks, which in the medium and long-term are relevant for structural integration into the labour and housing market. Network theory is a wellestablished field in migration research (ScOTT and CARRINGTON, 2011) and many recent studies have focused on the functionality of social networks for the integration process of migrants (GuraK and CACES, 1992; Massey et al., 1998; Haug, 2008; Poros, 2011, a, b; Cheung and Phillimore, 2013). The concept of social networks includes relationships between individuals and refers to the set of social contacts of an individual, made 
through personal relationships (VERTOVEC, 2002). Social networks have not only a social but also a productive value and thus may be of specific relevance for certain groups of migrants (ANDERsSon, Burgess and LANe, 2009).

Interest in social networks is mainly related to the fact that migrants with more elaborate networks have been shown to have greater socioeconomic success, better access to resources, more efficient facilities at dealing with everyday tasks. Thus, positive outcomes in an immigrant's life seem to be shaped by their quality of access to social networks (ELSNER, NARCISO and THIJSSEN, 2014).

In this context, only a few qualitative investigations among refugees have been done to provide adequate information for generating hypotheses (see the German study of BRÜCKER et al., 2016). Thus, a qualitative and somehow exploratory study of this kind may act as a valuable starting point for more detailed and rigorous research in the future. There have been some qualitative studies looking at refugee integration and adaptation (see for example Atfield et al., 2007; Montgomery, 1996). However, there is still a need for research around refugee integration that focuses on a range of dimensions, their interconnectedness and the way that they are experienced (GraBSKA, 2006; KORAC, 2003; SchiBeL et al., 2002) because in refugee research specific questions of methods and ethics are particularly relevant (JACOBSEn \& Landau, 2003; Temple \& Moran, 2006).

\section{Research focus}

This contribution offers an analysis of the modes and outcome of refugee social interactions with members of the Austrian receiving society. There is the theory-guided assumption that these initial contacts have an impact on the formation of weak ties and networks which are subsequently relevant for social integration. The analysis further investigates the composition and relevance of social relationships of refugees in different settings. In analysing the outcome of these social ties, the role played in the refugees' integration process by weak and strong ties with Austrians is also analysed.

The temporal plane of reference is mainly the initial and early phase of stay. In some cases refugees who have been in Austria longer - and mainly in examining housing and labour market integration and longer established social ties - were included in the analysis. As a hypothesis, it is suggested that bridging appears to play a more important role in the initial phase of stay. The question of how things develop after a longer period of time remains somewhat open, as there were only a few such persons in our narrative material sample.

The spatial plane can be found in refugee shelters, private accommodations, NGO offices, but also in places of "normal" daily life such as restaurants, education institutions, private apartments, public space, etc. 
The project was carried out to address recognised gaps in knowledge about the relationship between social contacts and integration. It offers an insight into the complex interrelationship of weak and strong ties, their relevance for social integration, and other indicators that are important at this early phase of their stay. Thus, a more precise examination of why and how refugees establish social ties and access networks will be necessary. Bonding and bridging per se allow for few conclusions, of whether these strong or weak social ties lead to resources, help and support and how relevant these resources are for the integration process. The more types of interactions refugees maintain, the more potential and likelihood there is for the development of further networks. Our qualitative material may not be able to provide a clear answer to the debate about the merits of weak and strong ties within the context of bridging capital as some information is rather fragmentary and thus inaccessible to systematic interpretation. In this way, the paper may also contribute to a better understanding of networking strategies and the particular manner in which new social ties were built before and after refugees' moving from NGO-assisted refugee accommodations to a more permanent place of living.

\section{Methodical considerations}

The method of qualitative content analysis (MAYRING 1996, 2000) was used as a guiding tool for the analysis of the data. The qualitative approach allowed for an exploration of the personal experiences of the respondents. Content analysis is an interpretative research approach to understand how the refugees partake in social contexts and make sense of them. (Jovchelovitch and BAuer, 2000; Gültekin et al., 2003).

\section{The relevance of weak and strong ties in the integration process}

The analysis of the interview transcripts resulted in the construction of two main fields important for the interpretation of the process of establishing weak and even strong social ties and determining their role in integration.

$>$ In social integration the main contexts were: Arriving, living in asylum accomodation, solving initial problems in Austria, interactions with NGO staff and volunteers, language learning, leisure activities, and meeting people in religious institutions. 
Of the fields of structural integration mentioned by EsSER (2001), housing and labour market integration were also included in the analysis as strong and weak ties turned out to play an important role there.

There is the dominant majority view that the experience of becoming a refugee is the cause of much personal suffering and severe social problems, and this cannot be disputed. A careful interpretation therefore needs to recognise the adaptive aspects in a biographical account, that is, how individuals are coping with the challenges of the actual situation and how successful some individuals are in their adaptation to the receiving society and its institutions, establishing strong and weak social ties and making use of them. Almost all of the interviewed refugees were prone and highly motivated to establish social contacts with the established community, though not all were really maintaining (self-selected) social interactions with Austrians.

There were many strategies in order to solve the manifold problems of "arriving" in Austrian society. One of the most important strategies was the search for social support. Due to strong family ties, many respondents from were able to use family support to solve their practical problems of integration. In many interviews, family members were mentioned as the first resort and source of advice, understanding and help. The interviewees relied on their family members for instrumental, social and emotional support. Social support was found to be an important factor which facilitated the participants' ability to adapt to life in Austria. Those, who had lost their family network were eager to establish new social ties to compensate for the social vacuum.

Instrumental support consisted of material help, such as financial assistance, provision of initial accommodation, help with the immigration process, and arranging necessary documentation for the asylum process. This instrumental support also provided newcomers with relevant information about services and social structures. A considerable degree of instrumental support was provided by professionals as NGO staff, rather than by help from private, civil society.

\subsection{Determinants of establishing social ties}

\subsubsection{Individual motivations and sociability}

As all refugees have to accept the loss of contact with former friends, relatives and of established social networks in general, there is a social vacuum which most of them want to refill with new social contacts. Severing contacts with the close friends and family members is often a very traumatic loss due to emigration (MAYDELL-STEVENS et al. 2007). Nonetheless, individual factors are also important in shaping the individual's sociability. Active individual efforts to establish social contacts are a very relevant factor in the formation of social ties. Thus, to a high degree it is dependent on the refugee's 
personality structure how quickly and easily they create an individual contact network. Starting with a basic network, some are very adept at further diversifying it. Those persons using a rather "strategic approach" are very successful in promoting their own social integration.

Interviewer1: "So you found it quite easy to find friends, to integrate, to, you know, find your way. It looks like that to me. Was it difficult for you?" S13: "To, it was not difficult, but it's always difficult in the relationship, to find the good person, but it's not difficult to say to any person: "Hello, how are you? My name is this, what's your name, and your son and my son are in the same class." It's easy. We work together, but when I say friends, that my friends, they are very close to me." (Syria 13, female, 38, al-Hasaka, Muslim, Arab).

'Yeah, not 'Migranten mentor', I know the 'migrant mentor' of my husband, Mr. M., but I have my own friends, Austrian friends, I have Rechtsberater, I have friends from Diakonie, there is a friend, I have a friend from the schools, Austrian friends from my kids'schools, the mothers, the parents, and also now I'm helping a lot my, my Kollegin in Diakonie to learn Arabic [...] Yeah, I teach them Arabic, I teach them Arabic. Somehow to contact the people [...]. And maybe in this way we could go inside the society." (Syria 13, female, 38, al-Hasaka, Muslim, Arab).

"Yes okay and people are too nice but anyway we should contact with them. Without contacting them, they, I cannot show them my culture, or I cannot tell them that who am I, or about my culture [...] But thanks, when I meet people, they, I can explain to them about Syria, and I like the communication with them, and really I like that they are helping, ahm, everyone wants help" (Syria 15, male, 35, Kurdish, Muslim).

On the other side there is a quite considerable number of persons in our sample who have very little or even no interethnic contact with Austrians, except the formalised contact:

"I had no contact with anybody of them until that day when we were secreted to Graz, a governmental organisation received us and helped us somehow. They were able to help us in everything." (Syria 5, male, 30, Damascus, Muslim/Sunni).

\subsubsection{Language skills}

The more social interactions with locals the refugees maintain, the better their language competency and vice versa. Social contacts emerge as particularly important in relation to the improvement of basic language abilities obtained through language courses. There is no doubt that the frequency of refugee social contacts is affected by language competency and the amount of time they have had social ties with longer residents, in particular with Austrians having wider networks and providing support. 
Moreover, the literature on social capital usually argues that contact with predominantly co-ethnic, national or religious groups and non-contact with out-groups is harmful to integration and may lead to further social fragmentation (Putnam 2007; see FinNeY \& SiMPSON 2008 for detailed discussion).

There is clear evidence in our analysis of the particular importance of language competency for the process of social integration. Those respondents with good Germanlanguage skills were likely to fare better in almost every domain. Given the importance of language to integration, and literacy to social mobility, it is particularly worrying that despite refugees placing so much value on language competency many refugees with poor language skills had no or very late access to more language training or found that training did not help them to develop the language as after finishing the course, they had quickly lost some or most of their competence:

"Yes, with Austrians I have contact, with men and with women. My problem is not the contact, but rather the language. I only speak very little German" (Irak 12, female, 50, Shêxan/Bagdad, Kurd, Yezidi).

"When I was new in Austria I had no intensive contacts with Austrians. I live in an asylum shelter and all the people I met there were from oriental countries. [...]At that time the problem was the language. If I would have been able to speak German coming into contact would have been easier for me." (Irak 10, 35, Mosul, Kurd, Yezidi).

"In this area for example, in the beginning I stayed two years there, I spoke the language, but I had troubles and could not really learn, really now after some time I was able to find my way with my friends, I found Austrian friends and I can communicate with them. Now my heart became brighter. So it is not important where one is living [...]. " (Afghanistan 17, male, 21, Ghazni, Hazara, Shiite).

"In the beginning, yeah, in the beginning was so difficult, because we have no languages, the German language. "(Syria 13, female, 38, alHasaka, Arab, Muslim).

\subsubsection{Time and duration of stay}

Among the "objective" determinants promoting social interactions and the development of social ties, time plays an important role; a longer duration of stay usually makes it possible to establish a bigger number of social ties:

“... and otherwise not too much, because I haven't been there very long, thus I don't have many friends" (A8, male, 24, Laghman).

"Ahh, I am still here not very long, I don't have contacts with Austrians. In the place where I lived before did only say 'hello'”' (A12, male, Konar). 
During the stay in refugee accommodation there were few chances to establish interethnic social ties with Austrian people. With a longer duration of stay new social contacts could be established:

"I did not make really experiences. During the first four months I had not any contact to anybody. I did not go out and did not take actions outside." (Iraq 3, male, 27, Turkoman/ Kurd, Muslim/Sunni).

"After some time we slowly, slowly also found other social contacts here." (Iraq 16, male, 30, Slemani/Bagdad, Kurdish, Muslim/Sunni).

\subsubsection{Participation in educational activities}

Our material also shows that involvement in education in general and in particular German language courses are a very important field of social interactions and of making new contacts. Both weak and strong ties could be established. Though most social ties within the courses are maintained with compatriots, the interethnic ties can be divided into two categories: (1) with persons from other non-Austrian groups attending the same courses, and (2) with Austrian teachers. The following quotes provide an insight into the social ties established there:

"I know only some other people from my course, my teachers whom I like very much and I still have social contact with them, are very good people, who are always asking for me." (Afghanistan 13, male 36, Ghazni, Hazara, Muslim/Shiite).

"I have a lot of good friends, for example my teacher Professor $X$ in the adult education centre. She is really nice. Sometimes I speak English with her and she is speaking German. Otherwise not too many contacts, because I haven't been there very long. Thus, I don 't have many friends but with my schoolmates I am really very happy." (Afghanistan 8, male, 24, Laghman).

"[...] today my German language teacher she has comforted me. Suddenly I cried because of my mother, because it is a great worry to me. So she immediately hugged me and comforted me. She also became sad because of my sorrows. This was really touching for me. "(Iraq 8, female, 26, Bagdad, Arab, Sunni/Shiite).

\subsubsection{Participation in confessional activities}

Religious organisations seem to be of minor importance as contact arenas for the refugees in our sample or have been excluded because of personal reasons. Interestingly enough Muslim respondents did not mention mosques and religious institutions as important contact fields for establishing interethnic contacts with compatriots or Muslims 
from other countries. The reason may be that during the early phase of their stay in asylum shelters it was difficult to participate in the activities of mosque associations.

Some Christian refugees on the other hand highlighted the church as a place in which contacts and even friendships with members of the church community have flourished. In this context, one must clearly distinguish between NGOs with a certain religious background, e.g. Diakonie and Caritas, which are anchored firmly in Christianity and explicit religious organisations as churches and Christian parishes per se. The benefits of such friendships clearly transcended the spiritual dimension and provided secular support. Some refugees spoke of a friend from church providing material support to help in finding new accommodation or support with the process of being granted refugee status. Others spoke of how links to fellow churchgoers offered opportunities to establish routine, reciprocal weak ties that can develop over time into even closer friendships:

"I have contacts but very few, through the churches mostly. We identified some families and they liked to help us." (Syria 7, male, 43, Aleppo, Armenian, orthodox).

"Now there are people like there is someone called T, she is an employee in the University of Vienna. ..., I met her in the Austrian church in the $3^{\text {rd }}$ district. She is a very good-hearted woman and lives in Baden, not in Vienna." (Syria 1, male, 24, Homs, Christian).

Most of the contacts there were explicitly positive, but there were also some complaints about a lack of help which was initially expected on the basis of social contacts, which were sought there:

"I pay $€ 400-500$ a month. I don't have anything, except Sozialhilfe. [...]. I pay nearly more than half of the salary for the rent. For nothing. Also I need to help my sister in Syria. She was forced to move away from her home. She has two kids. She doesn't have any work. [...]. Nobody helped me with this issue. I talked with many churches, nobody helped me. I talked with many churches to help me with my rent. Nobody helped me." (Syria 1, male,

24, Homs, Christian).

\subsubsection{The spatial context}

The refugees usually show a high level of motivation to learn German and establish social ties with the Austrian population. This goes hand-in-hand with a desire for better social integration. Thus, an explicit preference for living in urban spaces due to the better opportunities for social interactions was sometimes verbalised:

"In the urban context I will have more possibilities to come into contact with Austrian people. By this it is easier for me to integrate and I will learn the language more quickly. In the countryside I perhaps have to live far from civilization and one has only very few 
contacts with the Austrian population" (Iraq 8, female, 26, Bagdad, Arab, Muslim, Sunni-Shiite).

This argument was contradicted by other respondents. So for example a female respondent from Syria stated considerable differences in the openness for social contacts and in their quality between smaller towns in Tyrol where she stayed before and the city of Vienna:

"For the people, very nice with me when I was in Tirol, they were very, very nice with me, actually I have to say. There are some faces I could not delete it from my memory. But, when I came to Vienna, Vienna is a work city. You could easily not know what's, the face of your neighbour, just near your door and you meet him in the building in the stairs, but you didn't know that he is, who is living there. You hear his voice every night, but you didn't know. It's a very busy life. And in Vienna it's very rare to face a Austrian people. It's so mixed. Maybe you talk with them German, it's okay, and then suddenly: no, no, I'm not, I'm from Serbia, from Poland. [...] But the difference between Syria and Austria, is the difference between tea and water. It's so different. As feeling, until now, it's still different. [...] You've changed the whole atmosphere. It's something different. It's not about bad and good but something totally, not comparable, you could not compare Syria and Austria." (Syria 13, female, 38, al-Hasaka, Muslim, Arab).

\section{The relevance of social interactions with Austrians during the initial phase of stay}

Many refugees acknowledged that they experienced how hard it was to start a new life in a foreign country from zero. Being refugees presented all of the respondents with serious practical problems and issues to resolve. In terms of practical, everyday problems, they stated that starting life anew, from scratch, as well as experiencing a language barrier and financial problems, were the most important challenges they had to face. Problems in speaking and understanding German made it difficult to re-establish themselves in the new environment and caused all participants some initial hardship. Some expressed their hope that the difficulties they had to face were only temporary and their life would become easier soon.

Emotional support from family members was considered by all respondents to be very important. Friends, though less close and less numerous than they were back home, were also named as an important source of emotional support. Support based on weak ties to Austrians was reported by single migrants and family migrants as well.

To help overcome this difficult initial period, weak and strong ties were of considerable value to some refugees, but other respondents hardly reported their relevance. Obviously there are considerable individual variations concerning the importance of 
interethnic ties in the early integration process. Also certain behavioural strategies were reported by the refugees. Avoiding communication and interaction was relatively often mentioned as a coping strategy to protect oneself from feeling inadequate, in particular in interaction with Austrian people.

As CASTLES et al. (2002) note, integration is an ongoing process that involves both migrants and members of the host society interacting in a range of different social settings. One very initial setting can be found in refugee homes or camps in which they have to live during the first months of their stay. Thus, interesting insights into the refugees' relationships with their immediate social environment in these homes are discussed below.

The establishment of social ties is a step-by-step process. Coping with challenges in the initial phase of social integration usually includes compulsory social contacts with the public administration and NGOs. There is clear evidence that in the early stages of residence, contacts with NGOs increases the chances of receiving help with housing and employment (Cheung and Phillimore 2013). These interactions were reported by almost all respondents in a very detailed way, mirroring the importance attached to them. A remarkable fact is the generally positive feedback and even astonishment about the police's friendly, cooperative and favourable approach, though it must not be neglected that there were some complaints about a lack of cooperation and support. The positive impression of the behaviour of Austrian executive officers is demonstrated in the following extracts from interviews:

\footnotetext{
"Yes, yes, really, the police was incredibly nice. Yes, really, I was shocked! In our Arabic countries the police are impolite and sometimes very nervous. But here they were incredible, I got the possibility to get a shower, they provided us with some clothing and even food. And sitting together we took some coffee. Yes, and the very next day a first interview for asylum procedure was made. " (Syria 3, male, 24, place of origin: unknown, Muslim).
}

The first were the police officers, who treated us really very well. We had nothing to eat the whole time. They did not hurt us. That is positive in Europe that the police is not allowed to beat you. From Iraq I know a different situation. Yes, they provided us some food and even children drinks [...]. " (Iraq 3, male, 27, Turkoman/Kurdish, Muslim/Sunni).

"When we came to Austria, the first nice idea that comes to me from the Austrian people is the police that they welcomed us at the airport, the first time I see the police is helping the people and carrying the luggage and take them inside [he laughed]. We have the opposite and from that it shows that the people are very good-hearted, and very kind". (Syria 7, male, 43, Place of origin: Aleppo, Armenian, orthodox).

Frequently mentioned by many respondents was also the friendly and pronounced service orientation of the public administration, which was often emphasised contrary to experiences which were made in the country of origin. On basis of their experiences, the 
conclusion was drawn that public authorities in Austria are not oriented towards selfish purposes, but strictly comply with formal rules. Along with this formal orientation, ethnic, national and confessional groups were treated equally. Members of religious minorities, Christians and Yezidi in particular, emphasised the obvious absence of any religiously motivated discrimination from official side. A further oft-mentioned topic was a generally high level of trust in public officials, for example in policemen and government representatives, but also in everybody who interacted with the respondents during their initial phase of arriving and staying.

Concerning NGOs, the picture of interactive experiences was throughout positive. NGO employees were open to newcomers entering the local community and provided manifold support:

\footnotetext{
"My first contacts were with two persons from the Red Cross. Their social manners were very good. [...] they even brought us some food to our room. A really friendly and helpful people there. "(Iraq 3, male, 27, Turkoman/Kurdish, Muslim/Sunni).

"In Vienna I stayed 8 months in an asylum shelter in Simmering. [...] The staff there was really wonderful. They helped me often, even if I had not asked for help. They even drew my attention to many things and gave me useful tips of which I otherwise would have known nothing." (Iraq 10, male, 35, Mosul, Kurd, Yezidi).
}

It must not be neglected that also a few number of negative stories were told:

\footnotetext{
"We were staying at X. camp, there is no other, just this in this area, [...]. I wear the white jacket and work with them. The original employees were wearing a jacket its colour was blue. There are most of them or all of them were bad, really bad they were treating the refugees in a strange way, they shout at the refugees. [...]" (Syria 5, male, 30, Damascus, Muslim/Sunni).
}

A specific contact quality with Austrians resulted from initial contacts in the mood of "welcoming culture" of summer and autumn 2015. Though these contacts were evaluated very positively, one may conclude that most of them have not resulted in the development of long-term social ties:

"When we crossed the Austrian border we wanted to travel to Vienna but we did not know how. Then we met three girls and a young man. These we asked for some help. Sorry, I have forgotten their names. They invited us into their car and then took us with them to Vienna. They even invited us to their place and provided us food and drinks. We were allowed to take some rest and even a shower. This was really very nice from them. These were the first persons with whom I had contact there. I was really completely astonished. Though I was a stranger and came from a foreign country they looked after us really affectionately." (Iraq 9, male, 23, Bagdad, Arab, Sunni-Shiite). 
Some refugees mentioned the highly emotional quality of support which was provided by social ties to Austrians:

"Austrians are giving consolations if somebody is sad. They support you. And shortly before a friend of mine died in Iraq. As soon as they heard about it they all came and hugged me an gave consolations to me. And always when I want to talk they listen to me. [...] This I really enjoy from the Austrians. [...]. I find it wonderful that they voluntary help in refugee shelters and that they donate goods for us." (Iraq 8, female, 26, Bagdad, Arab, Sunnit/Shiit).

Some of these coincidental relationships of rather weak tie quality proved considerably sustainable and helped the refugees a lot in gaining a foothold in the receiving society. Thus, in some cases a long-term perspective of interethnic social interaction has developed:

"Now there are people like there is someone called T. She is an employee in the University of Vienna. [...] She is a secretary in the university and since she met me in the church she liked to help me in learning the language. To help me and bring me some books to read. Also she invited me to her home. I went to her, then we went shopping together and we ate together. Then I went back to Vienna. And she is always talking to me for example: "When do you like to come to me? I am here. When do you have time to drink coffee?" I am, for example, after I finish [work] at the university, we may meet in any café in Vienna." (Syria 1, male, 24, Homs, Christian).

A further special case were interactions by social media which without no doubt are very important as most of our interviewees confirmed. Though most of these digital contacts are with co-ethnic friends and family members there were also interethnic contacts:

"I had no camera and no laptop when I arrived in Austria. As soon as they heard about my photographic activities they started a Facebook call. Within a few hours I got a whole camera equipment, camera, lens and camera stand. I never have experienced such a helpful people. These are my experiences [...] Yes, and now they also found a German language course for me and they have registered me. It takes place in a certain school with two private teachers." (Iraq 3, male, 27, Turkoman/Kurd, Muslim/Sunnite).

\section{The relevance of social ties in structural integration: The long-term perspective}

The majority of refugees interviewed outlined broadly optimistic opinions of the integration process. The idea of learning, of making social contacts and of making a contribution to the new community in which they found themselves was strongly 
expressed. In many respects the respondents were keen to emphasise the positive aspects of their new lives in Austria. Involvement in the local community, fitting in with their new social contact partners and contributing via paid work were all seen as important aspects of their personal integration and ultimately steps on the way to "arrival" in Austrian society.

\subsection{Housing market integration}

Housing market integration is one of the most important fields in the context of structural integration (Castles et al 2002; Esser 2001). In some cases it turned out that even weak ties proved to be very effective in organising housing opportunities for the respondents:

"My first experiences with Austrians were excellent. Actually, I am sharing a flat with an Austrian. He provided me his flat although he doesn't really know me. He left his bedroom to me and my brother and he himself is sleeping in the smaller room. Though he does not know me, he did this all for me. Now, he is supporting us to find a German language course. Not even your close relatives would do this for you. The Austrians are really extraordinarily helpful and very affectionate people" (Iraq 1, male, 35, place of origin: Bagdad, Turkmen-Arab, Sunni).

Obviously similar support in housing integration was provided by longer established strong ties with Austrians:

"Yes, a girl called X. was with me in the residential community in Hollabrunn. She is my closest friend and till today I live with her. She supported me in each problematic situation, [...] I live with her since one and a half years and now I am attending the evening school of the commercial academy for the third semester [...]" (Afghanistan 1, female, 20, Kabul).

"Then I have to mention my flat companion $N$. He is really a fantastic guy. [...] Now, we live together with his friend, [...] He has never given us the feeling that we are only guests there. On the contrary, rather he makes us feeling that his flat is also our home". (Iraq 2, male, 24, Sheikhan, Kurd, Yezidi).

In some cases cultural barriers of living together with persons not belonging to the nuclear or extended family produced initial reservations towards the housing situation. Even very emotional strong ties may have developed from this new mode of living together:

"[...] one nice girl she called me and she told me that there is one house with Austria to live. I say no, I want something alone, private. [...] Because we don't have this type of sharing, 
this is, we don't, we never, only we share, the family, they live together. [...] But friends or strangers never live together. So she told me that they are waiting for us and they prepared dinner and this. I felt shy to say no. [...] We are sharing the kitchen and the bathroom. I have one room alone, up. I, they show it to me, they organised the bed, the bedsheet, the towel and even they put, this is which really touch me, one, pot [vase] with flower on the table $[\ldots]$. So, $[\ldots]$ now we are sharing everything and our stories, our life. [...] And so I am lucky that I have them, and also they are lucky, I am a nice woman, and they are now experiencing, trying the Syrian food." (Syria 4, female, 53, Dar'a, Muslim).

There were also cases in which interaction experiences in the housing sphere have been characterised as highly negative or as rather ambivalent:

"My first contact was with a neighbour which was not so good. It was an older lady,. [...] She really insulted us over months. I always greeted her and then she insulted me." (Iraq 16, male, 30, Slemani/Bagdad, Kurdish, Muslim/Sunni).

\subsection{Labour market integration}

Inability to confirm their qualifications and get an adequate job, jeopardised by poor language skills, resulted in unemployment or engagement in low-skilled, and subsequently low-paid, jobs which put the refugees in the low-income strata. Some got the chance to do unskilled work in an asylum shelter:

"In Traiskirchen I worked in the kitchen. And there I have worked together with Austrians. My experiences during this time were rather good. I tried to speak German with them as good as I could and then some English". (Iraq 10, male, 35, Mosul, Kurd, Yezidi).

Already after a relatively short span of job search, experiences were mostly disappointing:

"And I'm trying to find a job as a translator or with asylum or in asylum shelter but I cannot find one. I have written applications and CV to whole of Austria. Caritas, Diakonie, but everybody said 'no'. And now I am registered at Step2job (a Caritas program for long-time jobless people) and today at 3.30pm I have an appointment there [...]. " (Syria 15, male, 35, Kurdish, Muslim).

Active support for labour market integration by Austrians was rather rarely mentioned. This is doubtless an outcome of the fact that most of our respondents were "newcomers" and thus not officially allowed to work because of their legal status. Among the rare reports about acquiring a job by weak ties with local people the path of taking up an occupation as a NGO volunteer was the most frequent: 
"In Diakonie, in the $15^{\text {th }}$ district, XX, I work there as a translator, I began with English, Arabic, Arabic-English, now I'm since four or five months I begin in German, they help me a lot, I have to say, if I have any mistake, they correct it, the way, it's okay. But I'm enjoying my two days there. [...] I was a client there. [...] And I do it, there is a Sozialberater named Brigitte, she said: Do you want to help us too? [...]. And then I start from, the beginning of last February. [...] Two days, from nine to two." (Syria 13, female, 38, al-Hasaka, Arabic, Muslim).

There were a few particularly successful examples of labour market integration due to human connections and social ties. The integration biography of Syria 14 gives a vivid description of the relevance of this aspect for gaining a foothold in the employment system and the diverse and ambivalent experiences he made in this matter:

"Erm, because I got such great support from Austrians .... Because of this I want to stay and to continue to work for Red Cross. I am here since two years and now I manage three shelters and my staff consists of Austrians. ... First there was my neighbour who supported me and then my integration boss and afterwards my boss at the Red Cross, they all have very well accepted me, though I was no(body), but simply they wanted to help me" (Syria 14, male, 34, al-Malikiya, Kurdish, Muslim).

A broad variety of answers regarding plans for the future was given: the desire to achieve a good education, a well-paid job, success, the acquisition of skills, mastering German, getting an adequate or even any job, studying and requalification, and achieving some financial basis. Only in rare cases was expecting support by Austrian friends for realising the future plans in labour market career a long-term perspective:

"I want to move to Klagenfurt, because I want to stay with this Austrian family. They live in a smaller village called Weiterndorf. Yes, I want to work there and after I have finished my studies I want to start a praxis there. I have a concrete plan and I want to move exactly to this place, yes because I want to live in a village not in a big city as Vienna. Because there it is so quiet and I like the nature" (Syria 3, male, 24, Muslim).

\section{Factors hindering social interactions}

The analysis of the barriers the refugees experienced in the early stage of adaptation to life in Austria led to the categories of practical problems, socio-cultural problems and psychological problems. Practical and socio-cultural problems were caused by external factors. Interconnected with practical problems were various socio-cultural problems described by the respondents. The new environment and language difficulties sometimes caused significant isolation from Austrian society, which manifested itself through a 
lack of understanding of cultural traditions and social norms, no contact with the host population and, as a result, a very secluded life.

\subsection{Language barriers}

Language problems were among the barriers which were most frequently mentioned by the refugees, e.g. lack of German competence, poor knowledge of English or the refusal of Austrians to communicate in English. The inability to speak and/or understand German or English was identified as particularly problematic in hindering the process of equal communication and interaction. Respondents clearly articulated that an inability to understand German was detrimental to integration. The evidence from our interviews supports the view that refugees identify the ability to communicate in German as a vital tool for enhancing social contacts and avoiding problems. Thus, all our respondents were very much eager to attend German courses and/or to improve their German by studying on one's own.

It became obvious that in this context there was a divide between the levels of educational attainment. Now, one may think that higher education usually protects refugees from discrimination and negative social contact experiences. However, the better educated who speak English fluently reported discriminatory social contacts more often, perhaps a result of their better language knowledge. Refugees only speaking their native language could not recognise this kind of discrimination. Thus, some of the better educated complained about employees of NGOs and public administration who were not able (or willing) to communicate in English. Thus, debates about the extent to which service providers have a duty to provide interpreters for refugees and discussions about the desirability of making English language proficiency a requirement are well rehearsed:

\footnotetext{
"In the beginning also we have a big problem with the language. I manage myself sometimes with English, but you know as an Austrian - Austrian people, they didn't prefer to talk in English and even in the, in Ämtern, they didn't. If you go to any, any official place and you begin to speak in English they immediately close. [...] They didn't accept it in any way. In Sozialamt, in AMS, what I used to go, for my papers, they didn't accept speaking English. They prefer gesturing to speaking English, yeah (laughs)" (Syria 13, female, 38, Place of origin: al-Hasaka, Muslim, Arab).
}

"[...] now, I don't feel as a stranger here. In the beginning it was difficult, because I always remembered my family, but after some time it became better. I learned the language, now I can communicate with people and I have no other problems now, inshallah" (A 16, male, 31, Laghman/Kabul). 


\subsection{Xenophobia}

A further barrier centres on the social reluctance of some members of the host community to interact with the new arrivals. In our sample relatively few refugees spoke of experiences in which rejectionist or even explicit xenophobic attitudes were demonstrated against them. This may be an outcome of the general mood of the political and media-fostered "welcome culture" which dominated the refugee discussion in Austria until the turn of the year 2015/16:

"Because we saw, when the refugees came in very big numbers and all people just were in panic, how to help them. Okay, maybe some of them, it's normal in every culture there is, you know, there is, who, national people, who don't like foreigners, it's normal, [...]." (Syria 15, male, 35, Kurdish, Muslim).

There seem to be strong interdependencies between language barriers and xenophobia. Thus, in some cases it may be rather difficult to assess to what extent xenophobic attitudes prevent Austrians communicating in English, or if a lack of competency may be the main cause:

"There are some Austrians who are xenophobic, but the rest is not so. Those who do not like foreigners can be identified by their behaviour. They are always answering in German. So, as an example, if I have a question and I ask in English, they intentionally give their answer in German. Though the Austrian notices that I am not able to speak German and though he would be able to speak English with me, he does not want to do this. Intentionally he speaks German only [...]. “ (Iraq 8, female, 26, Bagdad, Arab, Sunni/Shiite).

There were cases in which interaction experiences were characterised as very hostile:

"My first contact was with a neighbour which was not so good. It was an older lady, with a rather strange name, not really Austrian name. She really insulted us during months. I always greeted her and then she insulted me. Then, after my German language course I asked her why she hates me so. And the answered that she hates me because I am a Turk. Then I informed her that I am no Turk but I am Iraqi. Now, after this she left me in peace at least for some time, but one day she started again insulting us. But with another female neighbour we had a very good contact relationship. She visited us and brought us some sweets. This neighbour really helped us a lot." (Iraq 16, male, 30, Slemani/Bagdad, Kurdish, Muslim/Sunni).

Not explicit xenophobia but also a kind of general social distance in human interactions or even avoidance had been experienced: 
"It is true that this country is very progressive, but there is almost no social contact between people. There is no care for each other, there is no empathy or sympathy towards other human beings. There is no friend who suddenly knocks at the door and comes for some coffee. It is not only strange, that one is in a foreign country." (Iraq 12, female, 50, Shêxan/ Bagdad, Kurdish/Yezidi).

Social exclusion could also be produced not by xenophobia, but by formal circumstances and is an involuntary phenomenon. Exclusion from social life may be caused by the long wait for refugee status, not being allowed to work and thus the special legal status of asylum seekers:

"Yeah, I want to share, [...] erm, actually it's my fault, that ... but there's no chance. I'm not working, I'm not going to university, I'm not doing anything, so I can't meet people in the street or in bar, I don't like to talk to people like in this way, so I think later on when I have job, maybe I will, I'll try to do my masters at university, so maybe it will be chance to meet people" (Syria 12, female, 35, Banias, Alawi).

\section{Resume}

This chapter focused on the patterns of social adaptation of refugees in Austria. It investigated the determinants influencing the process of establishing social ties, factors that hinder refugees developing social relationships and examined strategies adopted by the refugees to solve their initial problems with the help of their social networks.

As the current project was a pilot and exploratory study, the purposive sampling of respondents with specific demographic characteristics does not allow for generalisations. The study focused mainly on the experiences of refugees who were recent arrivals and did not perceive themselves to have fully undergone the process of re-establishing social networks. Therefore, the findings derived on the basis of the interviews were quite idiosyncratic to this specific group. It will be necessary to investigate larger samples of refugees from various ethnic backgrounds and with different characteristics in order to produce a representative picture of the patterns of building up weak and strong social ties in a receiving society for refugees.

An interesting aspect was the self-evaluation of the quality of social ties by the refugees themselves. Many personal narratives of the refugees were even enthusiastic about the warm welcome and help that they had received. A justified conclusion might be that some statements may be exaggerated. In many cases these positive experiences were contrasted to the negative mood in their countries of origin and the absence of such solidarity. In many respects, refugees were very keen to emphasise the positive potential of their new social contacts. Involvement in the local community, fitting in with their 
new interaction partners and even contributing, if possible, are seen as important aspects of integration and first steps on the way to becoming established within the receiving society. To get involved in the receiving community and to gain some knowledge of where to go if they have a problem was an important output of initial social contacts and thus repeatedly stressed.

Across all three groups of origin accounts of negative relationships were by far outnumbered by the positive ones, but whereas Syrians had the most enthusiastic narratives, some Iraqis and in particular Afghanis were confronted with more barriers. Thus, in some cases they have made rather ambivalent or even negative interaction experiences.

There is clear evidence that the individual's personality is a crucial factor in the establishment of new social ties. The appraisal of the gains and losses from seeking refuge influenced the attitudes towards the new situation in Austria and had an impacted on the respondents' goals. The refugees who suffered most from the loss of their families and old friends, exhibited poorer social adaptation patterns and tended to show some preference for a separation strategy. In contrast, those who strove to create a new sense of belonging, as well as actively regain a sense of re-establishing social ties and social status, perceived their situation more as a challenge which can be overcome and an opportunity for self-development and the creation of new social networks. This strategy was the choice of those refugees whose plans for the future included achieving language fluency, retraining and requalifying; and those who sought employment and active engagement in the Austrian society.

Social support was found to be an important factor which facilitated the refugees' abilities to adapt to life. This support was provided by Austrian acquaintances and friends in the form of instrumental aid and emotional support. Weak and strong ties play an important role in both fields of integration, social as well structural.

There is further potential for research in this area and focusing upon enabling clearer distinctions to be made between different types of social ties. Given the multidimensionality of integration it is likely that looking only at the initial phase of establishing social interactions is too simplistic. Thus, a longitudinal view on social ties and the process of development and formation of stable social networks in the receiving society would be necessary. Due to the available material, a more systematic network oriented approach might show new results but could not possibly be carried out using our material. 


\section{Literature cited}

Ager A. (ed.) (1999), Refugees: Perspectives on the Experience of Forced Migration. Cassell, London.

Ager A. and Eyber C. (2002), Indicators of Integration: A Review of Indicators of Refugee Integration. Report to the Home Office on behalf of Michael Bell Associates.

Ager A. \& Strang A. (2004), Indicators of Integration: Final Report. London, Home Office. Available from: $<$ www.homeoffice.gov.uk/rds/pdfs04/dpr28.pdf $>$

Ager A., Strang A. (2008), Understanding Integration: A Conceptual Framework. Journal of Refugee Studies Vol. 21, No. 2, Oxford University Press.

Ager A., Strang A. (2010), Refugee Integration: Emerging Trends and Remaining Agendas. Journal of Refugee Studies, 23 (4), 589-607. <doi: 10.1093/jrs/feq046>

Ager A., Strang A., O’May F. \& Garner P. (2002), Indicators of Integration: A conceptual analysis of refugee integration (Version 5.7). A report to the Home Office on behalf of Michael Bell Associates. Croydon, IRSS, Home Office.

Andersson P.F., Burgess S. and Lane J. (2009), Do as the neighbors do: the impact of social networks on immigrant employment. IZA Discussion Paper (4223).

Atfield G., Brahmbhatt K. and O’Toole T. (2007), Refugees' experiences of integration, London. Refugee Council/University of Birmingham.

Berry J.W., Poortinga Y.H., Segall M.H., and Dasen P.R. (2002), Cross-Cultural Psychology: Research and Applications. ( $2^{\text {nd }}$ ed.), Cambridge University Press, Cambridge.

Brücker H., Fendel T., Kunert A., Mangold U., Siegert M. \& Schupp J. (2016), Geflüchtete Menschen in Deutschland. Warum sie kommen, was sie mitbringen und welche Erfahrungen sie machen. IAB-Kurzbericht 15. Nürnberg, Bertelsmann.

Castles S., (2003), Towards a Sociology of Forced Migration and Social Transformation. Sociology 37 (1), pp. 13-34.

Castles S., Korac M., Vasta E., Vertovec S. (2001), Integration: Mapping the Field. Report. Centre for Migration and Policy Research and Refugee Studies Centre, University of Oxford.

Cheung S.Y. \& Phillimore J. (2013), Social networks, social capital and refugee integration Research Report for Nuffield Foundation April 2013. University of Birmingham.

Dwyer P. (2008), Integration? The perceptions and experiences of refugees in Yorkshire and the Humber. Yorkshire and Humber Regional and Migration Partnership.

$<$ https://www.migrationyorkshire.org.uk/userfiles/file/PolicyandResearch/YHRMP Reports/YH_RefugeeFocusGroups_Nov08.pdf>

Elsner B., NArciso G. and Thisssen J. (2014), Migrant Networks and the Spread of Misinformation. IZA Discussion Paper 7863.

$<$ http://papers.ssrn.com/sol3/papers.cfm?abstract_id=2374644>

Esser H. (1999), Inklusion, Integration und ethnische Schichtung. Journal für Konflikt und Gewaltforschung, 1, Heft 1, pp. 5-34.

EsSER H. (2001), Integration und ethnische Schichtung. Arbeitspapier, 40. Mannheim. $<$ http://www.mzes.uni-mannheim.de/publications/wp/wp-40.pdf >

EsSER H. (2006), Migration, language and integration. AKI Research Review 4. Programme on Intercultural Conflicts and Societal Integration. Social Science Research Centre Berlin. $<$ http://www.aki.wz-berline.de> 
GrabsKa K. (July 2006), Who Asked Them Anyway? Rights, Policies and Wellbeing of Refugees in Egypt. Forced Migration and Refugee Studies, American University in Cairo, Egypt. $<$ http://www.migrationdrc.org/publications/research_reports/Kasia_Egypt_Research_ ReportEDITED.pdf>

Granovetter, M.S. (1973), The Strength of Weak Ties. American Journal of Sociology, 78 (6), (May, 1973), pp. 1360-1380.

GrifFiths D., Sigona N. and Zetter R. (2005), Refugee community organisations and dispersal: net works, resources and social capital. Bristol, Policy Press.

Gültekin N., Inowlocki L. \& Lutz H. (2003), Quest and Query: Interpreting a Biographical Interview with a Turkish Woman Laborer in Germany. FQS/Forum Qualitative Social Research, Volume 4, No. 3, Art. 20 September 2003.

$<$ http://www.qualitative-research.net/index.php/fqs/article/view/668/1444>

GURAK D.T. and Caces F. (1992), Migration networks and the shaping of migration systems. In: KRITZ M.M. (ed.), International migration systems: A global approach. Oxford, Clarendon Press, pp. 150-176.

Haug S. (2008), Migration Networks and Decision Making. Journal of Ethnic and Migration Studies, 34 (4), pp. 585-605.

Heckmann F. (2006), Integration and integration Policies. IMISCOE Network Feasability Study, efms INTPOL TEAM.

Hollands M. (2001), Upon Closer Acquaintance: The Impact of Direct Contact with Refugees on Dutch Hosts. Journal of Refugee Studies, 14 (3), pp. 295-314. <doi: 10.1093/jrs/14.3.295)>

Jacobsen K. \& LANDAu L. (2003), Researching Refugees: Some methodological and ethical considerations in social science and forced migration. New Issues in Refugee Research, Working Paper 90. Geneva, Evaluation and Policy Unit, UNHCR.

Jovchelovitch S. and Bauer M.W. (2000), Narrative interviewing (online). London, LSE Research. $<$ http://eprints.lse.ac.uk/2633/1/Narrativeinterviewing.pdf $>$

Kamali M. (1999), Distorted Integration: Problems of Monolithic Order, in Innovation. The European Journal of Social Sciences, 12 (1), pp. 81-97.

Kindler M., Ratcheva V. and PiechowsKa M. (2015), Social networks, social capital and migrant integration at local level. European literature review, IRIS WORKING PAPER SERIES, 6 (IRiS WP 6-2015 [PDF] - University of Birmingham).

Korac M. (2003), Integration and how we facilitate it: A comparative study of settlement experiences of refugees in Italy and the Netherlands. Sociology (BSA), 37 (1),: pp. 51-68.

Lockwood D. (1964), Social Integration and System Integration. In: Zollschan G.; HiRsCH W. [eds.]: Explorations in Social Change. Routledge \& K. Paul, London, pp. 244-257.

Massey D.S., Arango J., Hugo G., Kouaouci A., Pellegrino A. and. Taylor J.E (1998), Worlds in motion: understanding international migration at the end of the millennium. New York, Oxford University Press.

Maydell-Stevens E., Masgoret A.-M. and Ward T. (2007), Problems of psychological and sociocultural adaptation among Russian-speaking immigrants in New Zealand. Social Policy Journal of New Zealand, 30. <https://www.msd.govt.nz/about-msd-and-our-work/ publications-resources/journals-and-magazines/social-policy-journal/spj30/30-problemspsychological-sociocultural-adaptation-russian-immigrants-p178-198.html>

MAYRING Ph. (1996), Einführung in die qualitative Sozialforschung. Eine Anleitung zu qualitativem Denken ( $3^{\text {rd }}$ edition). Weinheim, Psychologie Verlags Union. 
MAYRING Ph. (2000), Qualitative Inhaltsanalyse. Grundlagen und Techniken (7 $7^{\text {th }}$ edition). Weinheim, Deutscher Studien Verlag.

McMichael C. \& Manderson L. (2004), Somali women and well-being: Social networks and social capital among immigrant women in Australia. Human Organisation, 63 (1), pp. 8899.

Montgomery J. R. (1996), “Components of Refugee Adaptation.” International Migration Review 30 (3), pp. 679-702.

Musterd S. (2003), Segregation and integration: a contested relationship. Journal of Ethnic and Migration Studies, 29 (4), pp. 623-641.

Perry J. (2005), Housing and support services for asylumseekers and refugees: a good practice guide.York, JRF.

Phillips D. (2006), 'Moving toward integration: the housing of asylum seekers and refugees in Britain'. Housing Studies, 21 (4), pp. 539-553.

Poros M.V. (2011a), Modern Migrations: Gujarati Indian Networks in New York and London. Palo Alto, CA, Stanford University Press.

Poros M.V. (2011b), Migrant Social Networks: Vehicles for Migration, Integration, and Development. Washington, D.C., Migration Policy Institute.

Portes A. Quilgars D., Burrows R. and Wright K. (2003), Refugee housing and neighbourhood issues: a scooping review. York, Centre for Housing Policy, University of York.

Portes A. and Rumbaut R.G. (2001), Legacies. The story of the immigrant second generation. Berkeley, University of California Press, New York, Russell Sage Foundation.

Putnam R.D. (2007), 'E pluribus unum: civic engagement in a diverse and changing society'. Scandinavian Political Studies, 30(2).

Rosenberg, A. (2008), The integration of dispersed asylum seekers in Glasgow. PhD thesis, Univ. of Edinburgh, Edinburgh Research Archive. <oai:www.era.lib.ed.ac.uk:1842/3436>

Ryan L., Erel U. and D'Angelo A. (2015), Introduction. Understanding Migrant Capital, pp. 3-17. In: Ryan L., Erel U., D’Angelo A., Hetherington P. (eds.), Migrant Capital. Networks, Identities and Strategies, Palgrave, Macmillan, UK.

Schibel Y, Fazel M, Robb R. and Garner P. (2002), Refugee Integration: Can research synthesis inform policy? Feasibility study report. RDS online Report 13/02.

Scott J. and CARrington P.J. (2011), The SAGE handbook of social network analysis. Thousand Oaks, SAGE publications.

SIMPSON L. and NisSA F. (2008), Spatial patterns of internal migration: evidence for ethnic groups in Britain. First published: 17 December 2008. <doi: 10.1002/psp.497>

Spencer S.E. (2006), Refugees and Other New Migrants: A review of the evidence on successful approaches to integration. A report commissioned by the Home Office. Oxford, COMPAS.

Temple B. and Moran R. (eds.) (2006), Doing Research with Refugees: Issues and guidelines. Bristol, Policy Press.

VERTOVEC S. (2002), Transnational networks and skilled labour migration. ESRC Transnational Communities Research Programme Working Papers, 2 (2).

WALSH S.D. and HoREnczYK G. (2001), Gendered patterns of experience in social and cultural transition: The case of English-speaking immigrants in Israel. Sex Roles, 45(7-8), pp. 501528.

WARD C. (1996), “Acculturation”. In: LANDIS D. and BHAGAT R.S. (eds.) Handbook of Intercultural Training. ( $2^{\text {nd }}$ ed, pp. 24-147), Sage Publications, Thousand Oaks, California. 
Ward C., Bochner S. and Furnham A. (2001), The Psychology of Culture Shock. Routledge, Hove, England.

WENGRAF T. (2001), Qualitative research interviewing: biographic narrative and semi-structured method. London, Sage Publications.

Wengraf T. (2004), The Biographic-Narrative Interpretive Method (BNIM) - Shortguide November 2004. version 22, Middlesex University and University of East London. $<$ http:eprints.ncrm.ac.uk/30>

Williams L. (2006), Social networks of refugees in the United Kingdom: tradition, tactics and new community spaces. Journal of Ethnic and Migration Studies, 32 (5), pp. 865-879. $<$ www.informaworld.com/smpp/section?content=a747684010\&fulltext $=713240928>$

Zetter R., Griffiths D. \& Sigona N. (2005), Social Capital or Social exclusion? The Impact of Asylum Seeker Dispersal on UK Refugee Community Organisations. Community Development Journal, 40, pp. 169-181. 
